\title{
Editorial: The "Greening" of the Canadian Journal on Aging
}

It seems appropriate that I should be writing an editorial on the greening of the Canadian Journal on Aging (CJA) on Earth Day. What steps has the CJA taken to reduce its ecological footprint and what additional steps can we take to make our ecological footprint even smaller in the future?

Around 2004, we officially began to accept manuscripts electronically. Now, probably half the manuscripts I receive come as electronic attachments. What I propose is that, starting with Volume 28, we will only accept electronic submissions, but even before this date, I would encourage everyone to send us their manuscripts electronically. Watch for new submission instructions on the inside cover of Volume 28(1), 2009.

Secondly, does an electronic version of the CJA exist and does it make a difference? In fact, there are two ways to access the CJA electronically. Through University of Toronto Press, there is CJA ONLINE. To use this service, you need to be a member of the Canadian Association on Gerontology (CAG) or a subscriber to the journal, and the CAG needs to notify University of Toronto Press that you are a member in good standing. This is not a seamless process. There are lags between when someone becomes a new member and when University of Toronto Press is notified. We are working to improve this system.

The other way of accessing the CJA is through Project Muse. If your university/institutional library is a member of Project Muse, then you can gain access to the CJA for free. I previously wrote about Project Muse in an editorial in Volume 25(1), 2006. Has it made a difference to the global reach of the CJA? Let me share some statistics with you about the top 10 accessed articles from the CJA between 2004 and 2008, according to Project Muse.

\section{Article}

Requests

"Characteristics of Family/Friend Care Networks of 1,073 Frail Seniors"

Fast, Janet, Volume 23(1), Spring/printemps 2004

"Cross-national Comparisons of Social Isolation and

Loneliness: Introduction and Overview"

de Jong-Gierveld, J. (Jenny), Volume 23(2), Summer/ été 2004

\author{
"Social Isolation and Loneliness: Differences between \\ Older Rural and Urban Manitobans" \\ Havens, Betty, et al., Volume 23(2), Summer/été 2004 \\ "Changes in Levels of Social Isolation and Loneliness \\ among Older People in a Rural Area" \\ Wenger, G. Clare, Volume 23(2), Summer/été 2004 \\ "Theorizing about Aging Well: Constructing a \\ Narrative" \\ Chapman, Sherry Ann, Volume 24(1), Spring/ \\ printemps 2005 \\ "European and Canadian Studies of Loneliness \\ among Seniors" \\ Perlman, Daniel, Volume 23(2), Summer/été 2004 \\ "Contextual Effects on Life Satisfaction of Older Men \\ and Women" \\ Bourque, Paul, et al. Volume 24(1), Spring/printemps \\ 2005 \\ "Old Age and Loneliness: Cross-sectional and \\ Longitudinal Analyses in the Tampere Longitudinal \\ Study on Aging" \\ Jylha, Marja, Volume 23(2), Summer/été 2004 \\ "Older Women and Sexuality: Experiences in Marital \\ Relationships across the Life Course" \\ Clarke, Laura Hurd, Volume 25(2), Summer/été 2006 \\ "Gender and Marital-History Differences in \\ Emotional and Social Loneliness among Dutch \\ Older Adults" \\ Dykstra, Pearl A. (Pearl Annette), and de Jong- \\ Gierveld, J. (Jenny), Volume 23(2), Summer/'été \\ 2004
}

Or over the same period, 233 articles from the CJA were accessed 37,405 times (including those in the table) by readers around the world. I have no basis for comparison, but the numbers in the table above, the total number of articles accessed, and the number of times articles were accessed seem impressive to me. My congratulations go out not only to the authors in the table but to all of the authors whose articles have been accessed through Project Muse.

These numbers, however, raise another question about the future of the CJA. In the past 12 months, the debate over open-access electronic journals has heated up as the Canadian Institutes of Health Research (CIHR), the National Science and Engineering Research Council (NSERC), and the Social Sciences and Humanities Research Council (SSHRC) have considered their policies and how research funding and support of scholarly journals 
will likely be tied to open-access publishing in the future. As a researcher, my heart tells me that free open-access is the way to go in the future. As an editor-in-chief, my head tells me that how one pays for a free, open-access electronic journal is a challenge.

Regardless of how the CAG and the CJA resolve the debate over open-access electronic journals, I am confident that the CJA will continue to go green and go global in the future.

As always, please contact me at mark.rosenberg@ queensu.ca if you have any thoughts about this editorial or any other aspect of the CJA.

Mark Rosenberg

Editor-in-Chief 